five centres for the treatment of nerve injuries, three in England and two in Scotland. Similar centres have been organized in Natal, India and the Middle East. Treatment often extends over long periods and rehabilitation is both general and specific, the former being designed to keep men fit mentally and physically and the latter to encourage fine coordinated movements and the recovery of tactile discrimination. It is often possible for a man to return to work or to military service before recovery is complete. R.A.F. pilots are even able to return to operational flying before they have completely recovered. While complete restoration of function occurs in only a minority of cases, it is remarkable how many patients are able either to return to their former work or to train for new jobs.

Research is also carried out at these beneficent centres. It provides a check on the efficacy of the treatment given and a clearer definition of the various types of injury. Much information is obtained by special methods of examination which could not be obtained in any other way. Animal experiments are also used, and Prof. Seddon thinks that only the balanced combination of this and clinical observation can provide steady progress. The help of the modern highlytrained veterinarian might well be enlisted here. Between three and four thousand cases have already been treated at these centres and, as Prof. Seddon says, the mass of information which is being obtained should greatly advance this branch of neurology.

\section{Emergency Lighting Systems}

A PAPER on the applications of emergency lighting systems with particular reference to battery equipments was read before the Institution of Electrical Engineers in London on November 11 by Mr. S. H. Chase, who pointed out that in recent years there has been an increasing call for the installation of emergency lighting systems. These can be provided by candles or nightlights, gas, dry- or wet-battery torches, accumulators, engine-generator sets, alternative independent mains supply, or by a combination of several methods. The amount of emergency lighting may range from an intensity equal to normal down to the minimum considered necessary for safety and continuation of essential services. The paper deals mainly with the use of accumulators for standby purposes, operated either manually or automatically upon failure of the mains supply, and capable of supplying loads for varying periods according to the class of installations,' which are grouped under five heads : theatres and cinemas, hospitals and nursing homes, public buildings, etc., factories and A.R.P. services.

\section{Modern Insulating Materials}

IN a paper on "The Control, Specialized Testing and Use of Some Modern Insulating Materials", Mr. A. R. Dunton (J. Inst. Elec. Eng., 90, Pt. I, No. 35 ; Nov. 1943) deals briefly with the details associated with the control of incoming materials to the factory, together with some special features ascociated with tests which have to be carried out in order that the performanoe of the materials under special conditions can be ascertained. To achieve this work, special testing apparatus has been designed from time to time, and brief reference is made to some of the problems which have to be solved in order to ensure that the insulating materials selected will fulfil the performances required. Suggestions are also made dealing with the question of finding substitutes for insulating materials in short supply, and some of the new materials introduced for this purpose are mentioned.

\section{Announcements}

Dr. R. E. Priestrey, vice-chancellor of the University of Birmingham, has been appointed an additional member of the Commission on Higher Education in the Colonies. The appointment has been made in consideration of the fact that Prof. A. V. Hill's absence in India makes it impossible for him to take part in the proceedings of the Commission for some time.

Dr. H. W. Thompson, lecturer in chemistry in the University of Oxford, will deliver the Tilden Lecture of the Chemical Society on January 20 at 2.30 p.m. ; he will speak on "The Scope and Limitations of Infra-Red Measurements in Chemistry".

THE trustees of the Miners' Welfare National Scholarship Scheme, established by the Miners' Welfare Commission for the provision of university scholarships for workers in or about coal mines and their sons and daughters, have appointed Principal J. F. Rees, of the University College of South Wales and Monmouthshire, Cardiff, to be a member of the selection committee to recommend awards under the scheme, in succession to Prof. J. F. Duff, who has retired after completing five years on the committee.

The Therapeutic Corporation of Great Britain has elected the following officers for the year 1944: Chairman, Board of Directors: Mr. H. Jephcott (Glaxo Laboratories, Ltd.), (succeeds Dr. T. B. Maxwell, May and Baker, Ltd.); Deputy Chairman, Board of Directors : Dr. F. H. Carr (The British Drug Houses, Ltd.), (succeeds Mr. H. Jephcott, Glaxo Laboratories, Ltd.); Chairman, Research Panel: Dr. A. J. Ewins (May and Baker, Ltd.), (succeeds Dr. F. L. Pyman, Boots Pure Drug Co., Ltd.); Leputy Chairman, Research Panel : Mr. F. A. Robinson (Glaxo Laboratories, Ltd.), (succeeds Dr. J. W. Trevan, The Wellcome Foundation, Ltd.). The Corporation has appointed Dr. Frank Hartley as secretary, to take up duties early in 1944. The new offices of the Corporation are at General Buildings, 99 Aldwych, W.C.2.

A course of twelve lectures on "The Psychology of Frustration and Fulfilment in Adolescence" has been arranged by the National Council for Mental Hygiene. They are being delivered in the Caxton Hall, London, S.W.1, on Tuesdays, beginning January 18, at 5.15 p.m. The lectures are specially addressed to those with social and educational interests. Dr. J. A. Hadfield will speak on the psychology of adolescence; Dr. Paula Heimann on the psychoanalytic approach; Mr. R. W. Moore, headmaster of Harrow School, and Mr. T. F. Coade, headmaster of Bryanston School, will discuss the teacher's approach to the problems of the adolescent boy; Miss L. V. Southwell, headmistress of St. George's School in Switzerland, will deal with the adolescent girl in boarding schools; and Miss Olive Willis, headmistress of Downe House, Newbury, will discuss the teacher's approach to the problems of the adolescent girl. Tickets (single lectures, $3 s$. $6 d$. ; course, $£ 1$ 10s.) can be obtained from the Secretary, National Council for Mental Hygiene, 39 Queen Anne Street, London, W.1. 